\title{
Commentary Brain dysfunction in sepsis: what can we learn from cerebral perfusion studies?
}

\author{
Luzius A Steiner
}

Department of Anaesthesia, University Hospital Basel, Spitalstrasse 21, CH-4031 Basel, Switzerland

Corresponding author: Luzius A Steiner, Isteiner@uhbs.ch

Published: 18 January 2008

Critical Care 2008, 12:107 (doi:10.1186/cc6217)

This article is online at http://ccforum.com/content/12/1/107

(c) 2008 BioMed Central Ltd

See related research by Thees et al., http://ccforum.com/content/11/6/R123

\begin{abstract}
Investigations on the relationship between sepsis, brain dysfunction, and cerebral perfusion are methodologically very difficult to perform. It is important to interpret the results of such studies in view of our limited ability to diagnose and quantify brain dysfunction and to consider our limited understanding of the mechanisms that lead to or are associated with brain dysfunction in sepsis.
\end{abstract}

Thees and colleagues [1] performed an interesting study in a group of patients who are difficult to investigate. They measured cerebral haemodynamics and $\mathrm{CO}_{2}$ reactivity in 10 mechanically ventilated patients with sepsis syndrome. They report normal global cerebral blood flow (CBF) and also normal responses to a decrease in the arterial partial pressure of $\mathrm{CO}_{2}$ assessed as critical closing pressure and $\mathrm{CO}_{2}$ reactivity. $\mathrm{CO}_{2}$ reactivity has previously been investigated in similar groups of patients but with inconsistent results. Bowton and colleagues [2] and Matta and Stow [3] found normal values, Terborg and colleagues [4] found impaired $\mathrm{CO}_{2}$ reactivity, and Bowie and colleagues [5] reported values ranging from reduced to exaggerated $\mathrm{CO}_{2}$ responses.

Brain dysfunction is a serious complication of sepsis. The severity of septic encephalopathy or sepsis-associated delirium (SAD) [6] is correlated with the global severity of sepsis and has been reported to be an independent predictor of death [7]. The mechanisms leading to SAD are not completely understood and include reduced CBF, disruption of the blood-brain barrier and cerebral oedema arising from the action of inflammatory mediators on the cerebrovascular endothelium, impaired astrocyte function, and neuronal degeneration [8]. Recent experimental work suggests that the complement cascade [9] and tumour necrosis factor [10] are key mediators of SAD. As a 'downstream' phenomenon of both, these reports document an aquaporin-4 overexpression with an increase in brain water content and apoptotic neuronal cell death.

Based on the data presented by Thees and colleagues, I would like highlight some of the difficulties that make clinical research on SAD such a challenge. The first challenge is to identify and possibly quantify brain dysfunction in patients with sepsis. In my opinion, it is very likely that the majority of the patients investigated by Thees and colleagues had SAD; however, the presented data are inconclusive. The electroencephalogram (EEG) was abnormal in all patients. Propofol and sufentanil were used to achieve a Ramsey score of 3 , doses are not reported, and it is conceivable that the sedatives interfered with the EEG interpretation. EEG is just one possible aid to diagnose SAD and is certainly not specific for this entity. Seven of the patients had a computed tomography (CT) scan, all of which were normal. This finding is difficult to interpret as CT is perhaps not the best tool to investigate patients with SAD. A recent magnetic resonance imaging study documented lesions in seven of nine patients with septic shock and brain dysfunction [11]. Two had ischaemic lesions and five had findings corresponding to vasogenic oedema, probably reflecting blood-brain barrier breakdown, a finding that is compatible with experimental research $[9,10]$. Upon neurological examination 3 days after discontinuation of sedation, four of the eight surviving patients had psychotic symptoms, none was oriented in regard to time and location, and five were disoriented in regard to person. A validated instrument to diagnose delirium was not used. Ideally, SAD should be diagnosed during the daily interruption of sedation. However, this is not always possible and recently a concept incorporating clinical testing, blood markers of neuronal or astrocyte damage (such as

$\mathrm{CBF}=$ cerebral blood flow $\mathrm{CT}=$ computed tomography; $\mathrm{EEG}=$ electroencephalogram; $\mathrm{SAD}=$ sepsis-associated delirium. 
neuron-specific enolase or S-100 $\beta$ ), electrophysiology, and possibly imaging has been proposed [6]. However, such a concept has not been validated, and in the absence of a gold standard, diagnosis of SAD will remain a challenge.

A second question that is prompted by the work of Thees and colleagues is whether we should expect global CBF and $\mathrm{CO}_{2}$ reactivity to be disturbed in SAD. Or if disturbed cerebral perfusion or vascular reactivity is present, is it the cause or consequence of the SAD? An early study found low CBF independent of arterial pressure in septic patients [2]. In a retrospective observation, hypotension was the only predictor of SAD [12], suggesting that low CBF and consecutive ischaemia play an important role in the development of SAD. In that study [1], the patients were carefully stabilized and CBF was in the normal range. CBF values are expected to vary considerably due to sedation and the age of the included patients, and in my opinion it is impossible to define a 'normal' CBF range for such a group of patients. Moreover, ischaemic changes in relatively small brain regions could be responsible for the development of SAD [11,13] and would not be detected with the methods used. Therefore, in my opinion, the fact that global CBF was normal at the time of measurement does not add to our understanding of SAD. What can $\mathrm{CO}_{2}$ reactivity tell us? $\mathrm{CO}_{2}$ reactivity is a relatively robust mechanism and in adults is independent of the endothelium [14]. Therefore, one could speculate that, in analogy to traumatic brain injury, severe brain dysfunction is necessary to disturb $\mathrm{CO}_{2}$ reactivity. The action of inflammatory mediators on the endothelium has been proposed as an important element in the development of SAD. Endothelial dysfunction would probably affect pressure autoregulation rather than $\mathrm{CO}_{2}$ reactivity. However, the recent literature on autoregulation in patients with sepsis is as inconclusive as that on $\mathrm{CO}_{2}$ reactivity $[3,15]$. Nevertheless, assuming that disturbed cerebrovascular reactivity is a consequence rather than the cause of SAD, it could inform on the extent of the effect of inflammatory mediators on the brain.

Investigations addressing SAD will remain difficult due to the problem of correctly identifying and quantifying this entity. The value of monitoring cerebral perfusion and cerebrovascular reactivity in this setting remains to be defined. However, further experimental and clinical investigations on SAD are important and carefully controlled studies like the work by Thees and colleagues are to be encouraged.

\section{Competing interests}

The author declares that they have no competing interests.

\section{References}

1. Thees C, Kaiser M, Scholz M, Semmler A, Heneka MT, Baumgarten G, Hoeft A, Putensen C: Cerebral haemodynamics and carbon dioxide reactivity during sepsis syndrome. Crit Care 2007, 11:R123.

2. Bowton DL, Bertels NH, Prough DS, Stump DA: Cerebral blood flow is reduced in patients with sepsis syndrome. Crit Care Med 1989, 17:399-403.
3. Matta BF, Stow PJ: Sepsis-induced vasoparalysis does not involve the cerebral vasculature: indirect evidence from autoregulation and carbon dioxide reactivity studies. $\mathrm{Br} J$ Anaesth 1996, 76:790-794.

4. Terborg C, Schummer W, Albrecht M, Reinhart K, Weiller C, Rother J: Dysfunction of vasomotor reactivity in severe sepsis and septic shock. Intensive Care Med 2001, 27:1231-1234.

5. Bowie RA, O'Connor PJ, Mahajan RP: Cerebrovascular reactivity to carbon dioxide in sepsis syndrome. Anaesthesia 2003, 58:261-265.

6. Ebersoldt M, Sharshar T, Annane D: Sepsis-associated delirium. Intensive Care Med 2007, 33:941-950.

7. Sprung CL, Peduzzi PN, Shatney CH, Schein RM, Wilson MF, Sheagren JN, Hinshaw LB: Impact of encephalopathy on mortality in the sepsis syndrome. The Veterans Administration Systemic Sepsis Cooperative Study Group. Crit Care Med 1990, 18:801-806.

8. Papadopoulos MC, Davies DC, Moss RF, Tighe D, Bennett ED: Pathophysiology of septic encephalopathy: a review. Crit Care Med 2000, 28:3019-3024.

9. Jacob A, Hensley LK, Safratowich BD, Quigg RJ, Alexander JJ: The role of the complement cascade in endotoxin-induced septic encephalopathy. Lab Invest 2007, 87:1186-1194.

10. Alexander JJ, Jacob A, Cunningham P, Hensley L, Quigg RJ: TNF is a key mediator of septic encephalopathy acting through its receptor, TNF receptor-1. Neurochem Int 2007, Aug 17 [Epub ahead of print].

11. Sharshar T, Carlier R, Bernard F, Guidoux C, Brouland JP, Nardi $\mathrm{O}$, de la Grandmaison GL, Aboab J, Gray F, Menon D, et al.: Brain lesions in septic shock: a magnetic resonance imaging study. Intensive Care Med 2007, 33:798-806.

12. Wijdicks EF, Stevens M: The role of hypotension in septic encephalopathy following surgical procedures. Arch Neurol 1992, 49:653-656.

13. Finelli PF, Uphoff DF: Magnetic resonance imaging abnormalities with septic encephalopathy. J Neurol Neurosurg Psychiatry 2004, 75:1189-1191.

14. Brian JE Jr.: Carbon dioxide and the cerebral circulation. Anesthesiology 1998, 88:1365-1386.

15. Smith SM, Padayachee S, Modaresi KB, Smithies MN, Bihari DJ: Cerebral blood flow is proportional to cardiac index in patients with septic shock. J Crit Care 1998, 13:104-109. 